disease was monotherapy with intravenous immunoglobulins (IVIG). Monotherapy with IVIG was used in 15 patients with MIS-C, while 8 of them were initially treated with the combination of IVIG and corticosteroids. One death case occured in the MIS-C group, and none in the Kawasaki group.

Multisystem inflammatory syndrome in children associated with COVID-19 is a new pediatric disease that is dangerous and potentially lethal. Although many clinical and laboratory findings overlap with Kawasaki disease, this disease requires intensive care treatment more often. It can also have a fatal outcome - therefore prompt recognition and early treatment are crucial.

\section{BIBLIOMETRIC ANALYSIS OF THE PEDIATRIC ARTICLES FROM THE CHILDREN'S HOSPITAL ZAGREB, UNIVERSITY OF ZAGREB, FROM 2010 TO 2019}

Tamara Marija Seme, Maja Batinica*. Children's Hospital Zagreb, Klaićeva 16, Zagreb, Croatia

10.1136/archdischild-2021-europaediatrics. 17

Bibliometric analysis gives an objective information about the rate and characteristics of publishing activity of individuals, groups and institutions, as well as its impact in scientific community. Secondary sources of information are essential in evaluation of scientific papers and in academic advancement. In the field of biomedicine and health relevant secondary sources are Web of Science Core Collection (WOSCC), Medline and Scopus. Goal Bibliometric analysis of the articles published by pediatricians (55) and pediatric residents (12), employees of Children's Hospital Zagreb for the period from 2010 to 2019 (total of 10 years).

Methods Source for analysis of publicistic productivity and of citation was eight WOSCC citation indexes. Search was performed in the period June 28th to July 10th of 2021, by the surname and name of each author, using Basic search and Author search. Meeting abstracts and corrections were excluded and results are limited to a range of years. Additional criterion was authors' address - meaning of institutional affiliation. The sample consisted of 343 articles, that were analyzed according to productivity markers (year of publication, journal title, language of the article) and citation.

Results The number of papers per author ranged from 0 to 108. In English were published 317 (92.4\%) papers, 25 (7.3\%) in Croatian language and 1 in Czech (0.3\%). Mostly papers were published in yr 2018 (57). The greatest number of articles $(50 ; 14.6 \%)$ was published in Journal of Pediatric Gastroenterology and Nutrition, then in Paediatria Croatica (28; 8.2\%), and in Clinical Nutrition (20; 5.8\%). Article impact was measured by number of citations. Citation analysis, done last week of August 2021, for the period from yr 2010, has confirmed that $295(86.0 \%)$ articles were cited. Sum of times articles were cited is 9.777 (without self citation 9.525 times). The most cited article has 783 citations, mean citation being 28.5 per article. Clinical guidelines, reviews and randomized clinical studies were the most cited papers and published by the highly ranked journals. Papers of group of authors of European associations confirmed the extensive participation in publishing high quality systematic reviews and review articles and involvement in the development of international clinical guidelines.

Conclusion Analysis confirmed significant contribution to professional and scientific community of pediatric professionals from Children's Hospital Zagreb, as well as the extensive involvement in the development of international expert recommendations.

\section{A COMPARISON OF THE CONNECTION BETWEEN THE MEDIA USE, SOCIAL AND INSTITUTIONAL SOURCES OF INFORMATION AND ATTITUDES ABOUT VACCINATION}

Željko Pavić*, Adrijana Šuljok, Aida Mujkić, Maja Miškulin, Ivan Miškulin, Vesna Višekruna Vučina, Zvjezdana Lovrić Makarić, Anita Dremel, Gordana Lesinger, Ljiljana Pintarić, Juraj Jurlina. Filozofski fakultet Osijek

\subsection{6/archdischild-2021-europaediatrics. 18}

Goal The aim of the research was to determine the influence of various media, social and institutional sources of information on attitudes about vaccination, i.e. on the belief in conspiracy theories in the field of vaccination. So far, some studies, especially in situations of vaccine confidence crises, showed that official sources of information (public media and the state institutions) and new sources of information, such as social media and the Internet, have different effects when it comes to vaccination attitudes. However, the topic is largely unexplored.

Methods The research was conducted on a convenience sample $(\mathrm{N}=916)$ of the Croatian population, and the data were collected by means of an online survey. As a criterion variable in the study, the result on the scale of belief in conspiracy theories in the field of vaccination was used. As the predictor variables, we measured whether the research participants used certain media (specialized and non-specialized Internet portals, television) professional literature (books and articles), social groups (family) and institutions (medical staff, educational institutions and state institutions) as the sources of vaccination information, whereas age and gender of the study participants were used as control variables. In addition to descriptive indicators (frequencies, arithmetic means, and standard deviations), linear regression analysis was used to verify the research questions.

Results Descriptive results show that citizens use different types of information on vaccination, but that the most common sources are specialized Internet portals (66.01\%), professional literature (53.55\%) and medical staff - medical doctors, nurses and pharmacists (43.72\%). The results showed that the use of non-specialized Internet portals $(\beta=0.27)$ and families $(\beta=0.18)$ as a source of information were statistically significantly $(\mathrm{p}<0.05)$ positively related, and that the use of medical staff $(\beta=-0.07)$, educational institutions $(\beta=-0.11)$ and state institutions $(\beta=-0.11)$ as sources of information negatively associated with belief in conspiracy theories. The use of television and professional books and articles did not prove to be significant predictors. Age was also not a significant predictor, while women showed a higher level of belief in conspiracy theories than men $(\beta=0.18)$.

Conclusion The results of the research show that the Internet portals are emerging as a new factor in creating negative attitudes about vaccination, which calls for further research. The traditional sources of information (television, professional books and articles), although often used, do not have a oneway impact. Social institutions as sources of information create positive attitudes about vaccination, while the positive and strong influence of the family as a source of information on belief in vaccination conspiracy theories implies the possibility that negative information about vaccination is often exchanged within the family. 